\title{
African eco-efficient solutions to food insecurity and climate change
}

\author{
Rolf Sommer · Juliet Braslow
}

Received: 19 May 2016/Accepted: 20 May 2016/Published online: 25 May 2016

(C) Springer Science+Business Media Dordrecht 2016

Let's be frank: we are making too little progress on protecting soils in sub-Saharan Africa from physical or chemical degradation!

First accounts of the pressing needs to conserve soils date back to British African colonial times:

At its meeting on the 20th October [1937] the Council of the Royal African Society, the President, the Earl of Athlone, in the Chair, passed the following resolution: «That this Council views with the gravest concern the widespread destruction of the African soil by erosion consequent on wasteful methods of husbandry which strike at the basis of rural economy and Native welfare, and is of opinion that immediate steps should be taken for the adoption of a common policy and energetic measures through British Africa in order to put an effective check upon this growing menace to the fertility of the land and the health of its inhabitants.»... With the object of drawing further attention to a problem of such gravity the Society's monthly dinner held at the Royal

R. Sommer $(\bowtie) \cdot$ J. Braslow

International Center for Tropical Agriculture, CIAT,

Nairobi, Kenya

e-mail: r.sommer@cgiar.org

J. Braslow

e-mail: j.braslow@cgiar.org
Empire Society's house on the 1st December was made the occasion for a discussion on the subject. (Royal African Society 1938)

80 years later, we are still discussing the same issues: Sub-Saharan Africa continues to face pervasive soil degradation and nutrient mining leading to low soil and water productivity, and subsequent low yields affecting the livelihoods of African farming communities. Climate change impacts only add to and complicate the dilemma.

Instead of discussing over a dinner at the Royal Empire Society's house, concerned scientists met at the 20th World Congress of Soil Science (WCSS) in 2014 in South Korea for a session on African EcoEfficient Solutions to Food Insecurity and Climate Change. Participants exchanged ideas about how soil science expertise can be applied to develop potential solutions to food production constraints, climate change impacts, and soil and land degradation in Africa. Presentations included eco-efficiency of integrated soil fertility management, an ecosystem services lens to bring a landscape scale perspective to land degradation problems, research aimed at reversing and mitigating land degradation through refocused investment by donors and governments, and adoption of site-specific, equity-sensitive strategies.

This special issue includes papers presented at the 20th WCSS, but also adds further, more recent, research tackling the issue. The nine publications 
cover field to landscape level research, measures to improve the productivity in an eco-efficient way and thus to narrow crop yield gaps, while addressing soil fertility and nutrient constraints. Conservation Agriculture (CA) and Integrated Soil Fertility Management (ISFM) - two prominent and widely promoted soil conservation practices-are covered in four articles, one of them addressing the issue whether $\mathrm{CA}$ is actually climate smart.

The objective of the special issue is to present African solutions aimed at reversing land degradation, increasing sustainable intensification and making agriculture climate smart.
Hopefully these context-specific solutions and approaches will lead us to see less talk and more action to address food insecurity and climate change from the ground up when future generations look back 80 years from now.

\section{Reference}

Royal African Society (1938) Land usage and soil erosion in Africa. Suppl J R Afr Soc 37:3-19 